\title{
Two distinct mechanisms for loss of thioredoxin-binding protein-2 in oxidative stress-induced renal carcinogenesis
}

\author{
Khokon K Dutta ${ }^{1}$, Yumiko Nishinaka ${ }^{2,3}$, Hiroshi Masutani ${ }^{2,3}$, Shinya Akatsuka ${ }^{1}$, \\ Than T Aung ${ }^{1}$, Tomoyuki Shirase ${ }^{1}$, Wen-Hua Lee ${ }^{1}$, Yoshihiro Yamada ${ }^{1}$, Hiroshi Hiai ${ }^{1}$, \\ Junji Yodoi ${ }^{3}$ and Shinya Toyokuni ${ }^{1}$
}

${ }^{1}$ Department of Pathology and Biology of Diseases, Graduate School of Medicine, Kyoto University, Kyoto, Japan; ${ }^{2}$ Biomedical Special Research Unit, Human Stress Signal Center, National Institute of Advanced Industrial Science and Technology (AIST), Ikeda, Osaka, Japan and ${ }^{3}$ Department of Biological Responses, Institute for Virus Research, Kyoto University, Kyoto, Japan

\begin{abstract}
Thioredoxin is a major component of thiol-reducing system. Recently, we identified thioredoxin-binding protein-2 (TBP-2) as a negative regulator of thioredoxin. Here, we report the role of TBP-2 in oxidative renal tubular injury and the subsequent carcinogenesis by ferric nitrilotriacetate. TBP-2 was abundantly expressed in the rat kidney. Immunohistochemical analysis revealed that TBP-2 was present in association with nuclei and mitochondrial intermembrane space in the proximal tubular cells and coimmunoprecipitated with cytochrome $c$. After acute oxidative tubular damage, TBP-2 protein, but not messenger RNA, markedly decreased, demonstrating shortened half-life of this protein. Most cases of the induced renal cell carcinoma showed undetectable levels of TBP-2 protein, which was associated with the methylation of $\mathrm{CpG}$ island in the promoter region. Genome sequence analyses identified the poly-A tract in the $3^{\prime}$ untranslated region as a mutation hot spot in this rather nonselective environment. Collectively, the amounts of TBP-2 protein were inversely associated with proliferation of tubular cells, as evaluated by proliferating cell nuclear antigen. These results suggest that loss of TBP-2 is essential for proliferation of not only neoplastic but also non-neoplastic renal tubular cells, and that TBP-2 is a target gene in oxidative stress-induced renal carcinogenesis by ferric nitrilotriacetate.
\end{abstract}

Laboratory Investigation (2005) 85, 798-807, advance online publication, 18 April 2005; doi:10.1038/labinvest.3700280

Keywords: oxidative stress; carcinogenesis; kidney; thioredoxin binding protein-2; methylation of CpG island; PCNA; vitamin D; mitochondria

Oxidative stress is intimately associated with carcinogenesis. ${ }^{1}$ Iron is the most abundantly present transition metal in the human body, and iron overload has been shown to be associated with carcinogenesis ${ }^{2}$ presumably via its catalytic effect on the generation of reactive oxygen species (ROS). ${ }^{3}$ However, its precise molecular mechanism still remains unclear.

Administration of an iron chelate, ferric nitrilotriacetate (Fe-NTA), provides an intriguing model of iron-mediated oxidative stress-induced carcino-

Correspondence: Professor S Toyokuni, MD, PhD, Department of Pathology and Biology of Diseases, Graduate School of Medicine, Kyoto University, Yoshida-Konoe-cho, Sakyo-ku, Kyoto 606-8501, Japan.

E-mail: toyokuni@path1.med.kyoto-u.ac.jp

Received 16 January 2005; revised and accepted 4 March 2005; published online 18 April 2005 genesis: its intraperitoneal administration induces renal proximal tubular damage (as a consequence of the Fenton reaction) that ultimately leads to up to $90 \%$ incidence of renal cell carcinoma (RCC) in rodents. ${ }^{4-6}$ This model is characterized by (1) high incidence of pulmonary metastasis and peritoneal invasion, (2) increase in molecules covalently modified by $\mathrm{ROS}^{7}$ in the kidney during carcinogenesis, and (3) inhibition of not only acute renal tubular damage but also tumor incidence ${ }^{8}$ by pretreatment with a lipophilic antioxidant, $\alpha$-tocopherol. We previously reported an increase in a variety of oxidatively modified molecules such as 8-oxoguanine, ${ }^{9,10}$ thymine-tyrosine crosslinks, ${ }^{11}$ saturated and unsaturated mutagenic aldehydes including 4-hydroxy-2-nonenal (HNE) and malondialdehyde (MDA), and HNE- and MDA-modified proteins ${ }^{12-14}$ in the kidney after Fe-NTA administration. Recently, we identified the $p 15^{I N K 4 B}$ and 
$p 16^{I N K 4 A}$ tumor suppressor genes ${ }^{15,16}$ and the annexin 2 gene $^{17}$ as target genes in this model.

Thioredoxin (Trx) is a $12-\mathrm{kDa}$ ubiquitous protein that has disulfide-reducing activity within its consensus sequence (-Trp-Cys-Gly-Pro-Cys-) and is involved in a variety of cellular functions including proliferation, antiapoptosis and the activation of transcription factors. ${ }^{18-20}$ Trx constitutes one of the major reducing systems in the cell together with Trx reductase and nicotinamide adenine dinucleotide phosphate, reduced form (NADPH). ${ }^{21,22}$

In 1999, we identified a Trx-binding protein with a yeast two-hybrid assay and named it Trx-binding protein-2 (TBP-2); ${ }^{23}$ it was recognized that TBP-2 is identical to vitamin $\mathrm{D}_{3}$ upregulated protein-1 (VDUP-1) ${ }^{24}$ or thioredoxin-interacting protein. ${ }^{25}$ In a more recent work, we found that loss of TBP-2 plays an important role in human T-cell leukemia virus type I-induced T-cell transformation. ${ }^{26}$ In the present study, we examined the significance of TBP-2 in the Fe-NTA-induced renal cancer model of rats. TBP-2 was abundantly present in the rat renal proximal tubular cells. We report here for the first time that loss or decrease of TBP-2 was a common and critical process for renal tubular proliferation whether it was regenerative or neoplastic, and that TBP-2 was a possible major target gene in this oxidative stress-induced renal carcinogenesis.

\section{Materials and methods}

\section{Chemicals}

Ferric nitrate enneahydrate, $\beta$-nicotinamide adenine dinucletide phosphate (reduced form), cytochrome $c$, sodium pyruvate and sodium succinate were from Wako (Osaka, Japan); nitrilotriacetic acid disodium salt was from Nacalai Tesque Inc. (Kyoto, Japan). 2-( $p$-Iodophenyl)-3-( $p$-nitrophenyl)-5-phenyltetrazolim chloride and $\beta$-nicotinamide adenine dinucleotide (reduced form) were from Sigma (St Louis, MO, USA). All the chemicals used were of analytical quality; deionized water was used throughout. FeNTA solution was prepared immediately before use as previously described. ${ }^{12}$

\section{Animal Studies}

Fe-NTA-induced RCCs were produced according to a previously described protocol. ${ }^{27}$ The acute study of a single injection (15 mg iron/ $\mathrm{kg} ; 0,1,3,6,12,24$ and $48 \mathrm{~h}$ ) and the subacute study of repeated injections (5-10 mg iron/kg; 3 weeks) were carried out as previously described using 5-week-old specific pathogen-free male Wistar rats (Shizuoka Laboratory Animal Center, Shizuoka, Japan). ${ }^{9}$ Fischer-344 and Brown-Norway rat strains were obtained from Charles River Japan Inc. (Yokohama, Japan). The animals were killed and RCCs were collected 12-15 months after the completion of
Fe-NTA administration as described. ${ }^{27}$ Tumorous and nontumorous portions of renal tissues were excised and stored frozen at $-80^{\circ} \mathrm{C}$. A total of 22 cases of RCCs (one grade-1 tumor, eight grade-2 tumors and 12 grade-3 tumors, of which 13 showed pulmonary metastasis and six showed peritoneal invasion after classification as described ${ }^{27}$ ) and one case of adenoma were used.

\section{Antibodies}

Yat315 and Yat818 mouse monoclonal antibodies $\left(\mathrm{IgG}_{1}\right)$ were raised against full-length human recombinant TBP-2. These antibodies recognized rat TBP-2. ${ }^{26}$ Anti-mouse Trx rabbit polyclonal antibody that also recognizes rat Trx was used as described. ${ }^{28}$ Mouse monoclonal antibody against cytochrome $C$ (clone A-8) was obtained from Santa Cruz Biotechnology (Santa Cruz, CA, USA). Monoclonal antibody against proliferating cell nuclear antigen (PCNA; clone PC-10) was from Dako (Kyoto, Japan). Antiactin monoclonal antibody (clone MAB1501) was purchased from Chemicon International Inc. (Temecula, CA, USA). Horseradish peroxidase-conjugated rabbit antibody against mouse IgG was from Amersham Pharmacia Biotech (Tokyo, Japan), and biotinlabeled rabbit antibody against mouse IgG was from Dako.

\section{Immunoprecipitation and Western Blot Analysis}

Tissue lysates were prepared by homogenization in RIPA buffer $(20 \mathrm{mM}$ Tris, $0.1 \%$ SDS, $1 \%$ Triton $\mathrm{X}-100,1 \%$ sodium deoxycholate, $\mathrm{pH}$ 7.4) in the presence of protease inhibitors (complete mini, Roche), and the supernatants collected after centrifugation at $15000 \mathrm{~g}$ for $15 \mathrm{~min}$ were used. For cellular fractionation, tissues were homogenized in $0.25 \mathrm{M}$ sucrose solution using five strokes of a Potter-type homogenizer, and differential centrifugation was performed. The precipitate after $600 \mathrm{~g}$ centrifugation for $10 \mathrm{~min}$ was regarded as the nuclear fraction; the precipitate after $8000 \mathrm{~g}$ centrifugation for $10 \mathrm{~min}$ was regarded as the mitochondrial fraction; the precipitate after $105000 \mathrm{~g}$ for $60 \mathrm{~min}$ was regarded as the microsomal fraction; and the remaining supernatant was regarded as the cytosol. The protein concentration was determined with BCA protein reagents (Pierce, Rockford, IL, USA). Biochemical analyses were performed to ascertain the purity of each fraction. High amount of DNA content was considered as an indicator for the nuclear fraction. ${ }^{29}$ Succinate dehydrogenase activity as an indicator for the mitochondrial fraction was determined by estimating the reduction of 2-( $p$-iodophenyl)-( $p$-nitrophenyl)-5-phenyl tetrazolium chloride. ${ }^{30}$ NADPH-cytochrome $c$ reductase activity as an indicator of the microsomal fraction was determined by measuring the reduction of cytochrome $c$ at $550 \mathrm{~nm}$. The reaction was 
conducted at $30^{\circ} \mathrm{C}$ in a high ionic strength buffer as described. ${ }^{31,32}$ Lactate dehydrogenase (LDH) activity as an indicator of cytosolic fraction was determined by estimating the consumption of $\beta$-nicotinamide adenine dinucleotide (NADH) and the progression was observed at $340 \mathrm{~nm} .^{33}$

Immunoprecipitation was performed as described ${ }^{17}$ using $10 \mu \mathrm{l}$ of Yat315 monoclonal antibody added to $400 \mu \mathrm{g}$ of lysate in a $100-\mu \mathrm{l}$ volume. $\mathrm{IgG}_{1}$ immunoglobulin (Dako, clone DAK-GO1) was used as a negative control. The Sepharose beads were separated by centrifugation, and boiled with $50 \mu \mathrm{l}$ of sample buffer containing 2-mercaptoethanol for $3 \mathrm{~min}$. In all, $20 \mu \mathrm{l}$ of the supernatant was electrophoresed in each lane for sodium dodecyl sulfatepolyacrylamide gel electrophoresis (SDS-PAGE). Western blotting was carried out as previously described. ${ }^{34} \mathrm{NIH}$ image freeware (ver. 1.62, http:// rsb.info.nih.gov/nih-image/) was used for the densitometric analyses.

\section{Immunohistochemical Analysis}

Tissues were fixed with $10 \%$ neutral formalin overnight, embedded in paraffin, cut at $3-\mu \mathrm{m}$ thickness, and used for hematoxylin and eosin staining or immunohistochmistry. The avidin-biotin complex method with peroxidase was used for immunohistochemistry as described. ${ }^{10}$ Antigen retrieval with a standard microwave irradiation method in $10 \mathrm{mM}$ citrate buffer, $\mathrm{pH}$ 7.4, was used. For electronmicroscopic analyses, a pre-embedding method was used. Briefly, paraffin-embedded specimens were cut at $8-\mu \mathrm{m}$ thickness, and immunohistochemistry was perfomed as described above. 3,3'-Diaminobenzidine solution (Dako Liquid DAB, K3466) was used for color development. Thereafter, the specimens were immediately postfixed with $2 \%$ glutaraldehyde in $50 \mathrm{mM}$ phosphate-buffered saline, pH 7.4, for $45 \mathrm{~min}$, dehydrated in a graded ethanol series, and embedded in Epon 812. Sections were cut with a diamond knife on a Sorvall MT-5000 ultramicrotome, mounted on copper grids coated with polyvinylformal, left unstained or stained with uranyl acetate, and observed with a Hitachi HU-12A electronmicroscope.

\section{Northern Blot Analysis}

Total RNA was isolated by means of a modified acid guanidinium phenol chloroform method (Isogen, Nippon Gene, Tokyo). Poly(A)-rich RNA was isolated using oligo(dT)-latex beads (Nippon Roche, Tokyo). For Northern blot analysis, poly(A)-rich RNA samples $(2 \mu \mathrm{g})$ were separated by electrophoresis on a $1 \%$ agarose gel containing formaldehyde and transferred onto a nylon membrane. DNA fragments of rat TBP-2 (GenBank XM 215640: 510-1494) were amplified by PCR (sense, 5'CCTACAGGTGAGAACGAGATGGTG-3'; antisense,
5'-GGCAGAAAGCGTTGAGTAGTAGTACAGAT-3') using rat kidney cDNA as a substrate, purified and used as a probe after labeling with $\left[\alpha^{-32} \mathrm{P}\right] \mathrm{dCTP}$ by the random priming method (Megaprime DNA labeling kit, Amersham Pharmacia Biotech). Hybridization was performed as previously described. ${ }^{17}$

\section{Mutational Analysis}

Genomic sequences of TBP-2 were amplified using seven different sets (forward, F; reverse, R) of primers: F1 5'-(-1035)GTGGACACTCCCTTACTGC TTCCGT $(-1011)-3^{\prime}$ and R1 $5^{\prime}-(-355) C T C G T G C A C A$ GTTCTCCCATTGGCT( -379$)-3^{\prime}$ (681 base pairs (bp); base numbers calculated from the first ATG codon); F2 $5^{\prime}$-(-396)GTAAACAAGGACCAAGTAGCCAATG $(-372)-3^{\prime}$ and R2 $5^{\prime}-(+237)$ TTCTAGGAGAAGGG TGTCTTCATAG $(+213)-3^{\prime}$ (633 bp); F3 $\quad 5^{\prime}-(+465)$ AAGATTAATGTATTCGTGGGTTGTG $(+489)-3^{\prime}$ and R3 $5^{\prime}-(+1120)$ GAACATGCAGGAAACTTTCTTCTC (+1097)-3' (656 bp); F4 5'-(+ 949)ACTCCTGACTTAA TGGTGAGGCTT $(+972)-3^{\prime}$ and R4 $5^{\prime}-(+1651)$ AGG TGGGAGTTTGTTAGATGGGTT( + 1628)-3' (703 bp); F5 5'-(+ 1547)AGAGTTGAATACTCCTTGCTGGTGA $(+1571)-3^{\prime}$ and R5 $5^{\prime}-(+2314)$ TCTGAAACATTGGA GTTCAAGCAGA $(+2290)-3^{\prime}$ (768 bp); F6 5'-(+2168) AAATCTGAAAGTCTCCTCGCTCTTC $(+2192)-3^{\prime}$ and R6 5'-(+2938)GCTAAAGTGCCAAGAACATCACCT$(+2915) 3^{\prime}$ (771 bp); F7 5'-(+2905)ATTGATTCTAA GGTGATGTTCTTGG $(+2929)-3^{\prime}$ and R7 $5^{\prime}-(+3696)$ GGCAGAGGAAAACTGAAGATACCTA $(+3672)-3^{\prime}$ (792 bp). These amplified sequences covered all the exon sequences and more than $80 \%$ of the intronic sequences ( $\sim 95 \%$ of the total TBP-2 gene area). PCR was performed in a $12.5-\mu \mathrm{l}$ reaction mixture. The mixture contained $1 \times$ PfuUltra high fidelity (HF) reaction buffer (Stratagene, La Jolla, CA, USA), dNTPs (0.3 mM each) (Takara, Shiga, Japan), primers (5 pmol per reaction mixture), template DNA (30 ng) and 0.63 unit of PfuUltra HF DNA Polymerase (Stratagene, La Jolla, CA, USA). Amplification was carried out for 35 cycles $\left(30 \mathrm{~s}\right.$ at $95^{\circ} \mathrm{C}, 30 \mathrm{~s}$ at $58^{\circ} \mathrm{C}$ and $75 \mathrm{~s}$ at $72^{\circ} \mathrm{C}$ ), followed by a final $10-\mathrm{min}$ extension at $72^{\circ} \mathrm{C}$. A zero blunt TOPO cloning kit (Invitrogen, Carlsbad, CA, USA) was used according to the manufacturer's instructions. Sequencing was performed using chain terminating big dye (Applied Biosystems, Foster city, CA, USA) and the sequences were compared with the rat genome database (NCBI, http://www.ncbi.nlm.nih.gov/) to evaluate the mutations.

\section{Methylation-Specific PCR}

Genomic DNA was extracted as described, ${ }^{35}$ and methylation-specific PCR was performed as described. ${ }^{36}$ The primers used are summarized in Table 1. 
Table 1 Primer pairs for methylation-specific PCR

\begin{tabular}{|c|c|c|c|}
\hline Primer set & Sense and antisense primers & $\begin{array}{l}\text { Product } \\
\text { Size (bp) }\end{array}$ & $\begin{array}{c}\text { Annealing } \\
\text { temperature }\left({ }^{\circ} \mathrm{C}\right)\end{array}$ \\
\hline $\begin{array}{l}\text { Methylated } \\
\text { (Modified DNA) }\end{array}$ & $\begin{array}{l}\text { S:5'(-423)CGGTTTCGTTGATTGGTTAGAGGTTT( }(-398) 3^{\prime} \\
\text { A:5'(-309)TAACTTAACGCTCCACGCG }(-327) 3^{\prime}\end{array}$ & 115 & 64 \\
\hline $\begin{array}{l}\text { Unmethylated } \\
\text { (Modified DNA) }\end{array}$ & $\begin{array}{l}\text { S:5'(-421)GTTTTGTTGATTGGTTAGAGGTTTGGTAAAT }(-391) 3^{\prime} \\
\text { A:5'(-302)AACCACCTAACTTAACACTCCACACAAATACTA }(-334) 3^{\prime}\end{array}$ & 120 & 68 \\
\hline $\begin{array}{l}\text { Control } \\
\text { (Unmodified DNA) }\end{array}$ & $\begin{array}{l}\text { S:5'(-393)AACAAGGACCAAGTAGCCAATG }(-372) 3^{\prime} \\
\text { A:5'(-271)TGTCAAGCGGGAGCCGGAAA }(-290) 3^{\prime}\end{array}$ & 123 & 65 \\
\hline
\end{tabular}

S, sense; A, antisense; bp, base pairs.

\section{Results}

\section{TBP-2 and Trx Protein Analysis}

In this model, acute renal tubular necrosis is observed $3 \mathrm{~h}$ after an intraperitoneal administration of Fe-NTA (15 mg iron $/ \mathrm{kg}$ ). Necrosis is prominent at $24 \mathrm{~h}$, but tubular regeneration supervenes at $48 \mathrm{~h}$. After repeated administration of Fe-NTA for 3 weeks, little necrosis is observed but karyomegalic cells appear. ${ }^{9}$

TBP-2 was most abundant in the untreated rat kidney among the tissues examined by Western blot analysis (Figure 1a). However, the amount was significantly decreased to less than $10 \%$ of the original amount $12-48 \mathrm{~h}$ after Fe-NTA administration. After the repeated administration of Fe-NTA for 3 weeks, a significant decrease of the amount of TBP-2 was observed. Furthermore, 21 out of 22 RCCs $(95.5 \%)$ showed an undetectable amount of TBP-2. One adenoma (data not shown) and 1 RCC showed decreased amounts of TBP-2 (Figure 1b). The pattern of Trx protein expression was different from that of TBP-2 in that Trx protein was increased at $48 \mathrm{~h}$, and that RCCs showed different levels of Trx protein according to their malignant potential. Basically, high-grade carcinoma expressed higher amounts of Trx (Figure 1b).

\section{TBP-2 mRNA Analysis}

Notably, TBP-2 message remained at an almost constant level after oxidative renal tubular injury by Fe-NTA, and increased at $48 \mathrm{~h}$. RCCs showed significantly decreased levels of TBP-2 message (Figure 1c).

\section{Immunohistochemical Analysis}

By immunohistochemical analyses, TBP-2 was detected in the cytoplasm and nuclei of the renal proximal tubular cells, but not in the glomeruli. The cytoplasm showed a distinct granular pattern (Figure 2a). After oxidative tubular damage, the survived tubular cells lost the immunostaining (data not shown). After 3 weeks of Fe-NTA treatment, some renal proximal cells showed immunostaining, a $\mathrm{Ht} \quad \mathrm{Lg} \quad \mathrm{Lv} \quad \mathrm{Sp} \mathrm{Kd}$ Ts slnt $\mathrm{Cbr} \mathrm{Cbl}$

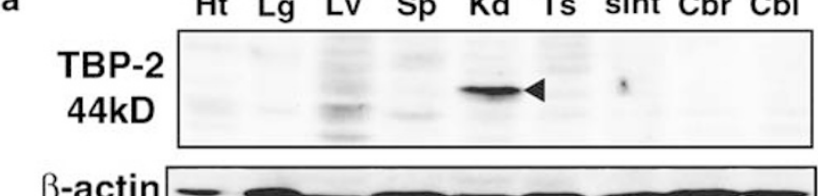

b

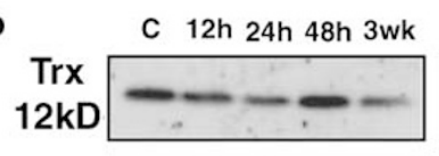
C Renal Cell Carcinoma
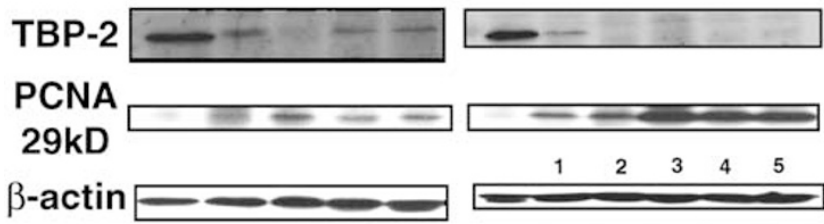
\begin{tabular}{|l|c|c|c|c|c|}
\hline Lung Metastasis & - & + & + & + & + \\
\hline Peritoneal Invasion & - & - & - & + & + \\
\hline
\end{tabular}

C

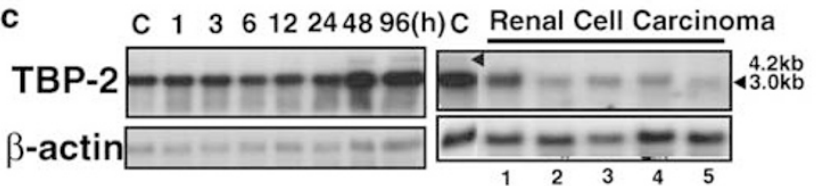

Figure 1 Characterization of TBP-2 expression in rat normal organs, kidney after Fe-NTA administration and Fe-NTA-induced renal cell carcinoma. (a) The highest level of thioredoxin-binding protein-2 (TBP-2) was detected by Western blot analysis in the kidney (arrowhead). Ht, heart; Lg, lung; Lv, liver; Sp, spleen; Kd, kidney; Ts, testis; sInt, small intestine; Cbr, cerebrum; Cbl, cerebellum. (b) Western blot analysis of thioredoxin (Trx), TBP-2 and proliferating cell nuclear antigen (PCNA). Decrease or loss of TBP-2 protein in the kidney was observed after an administration of ferric nitrilotriacetate (Fe-NTA; 12, 24 and $48 \mathrm{~h}$ ) or after repeated administration ( 3 weeks). Loss of TBP-2 was observed in most of the Fe-NTA-induced renal cell carcinomas (RCCs). Decrease or loss of TBP-2 was associated with increase in PCNA (refer to Figure 4). The Trx protein level was basically proportional with the malignant behavior of the tumor. C, untreated control kidney. See text for details. (c) Northern blot analysis of TBP-2 and $\beta$-actin. The levels of TBP- 2 message (lower arrowhead) remained almost unchanged or were rather increased after an administration of Fe-NTA (1, 3, 6, 12, 24, 48 and $96 \mathrm{~h})$, whereas that in the RCCs was significantly decreased. The samples of RCCs in (b) and (c) correspond each other (1-5). A minor band of $4.2 \mathrm{~kb}$ was observed (upper arrowhead).

but other cells including karyomeglic cells showed no staining (Figure 2e). RCCs showed undetectable levels of immunostaining (Figure 2f). 


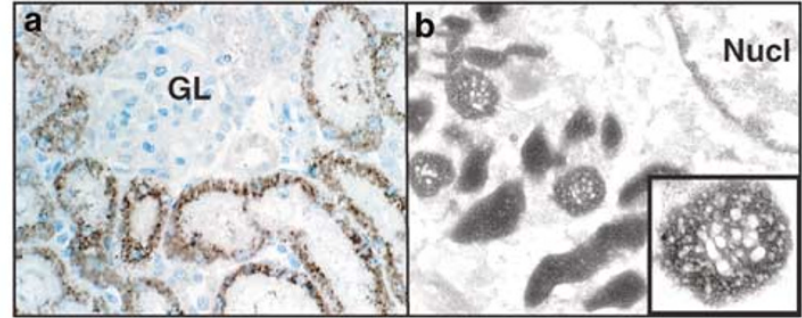

C

Nucl Mito Micro Cytosol
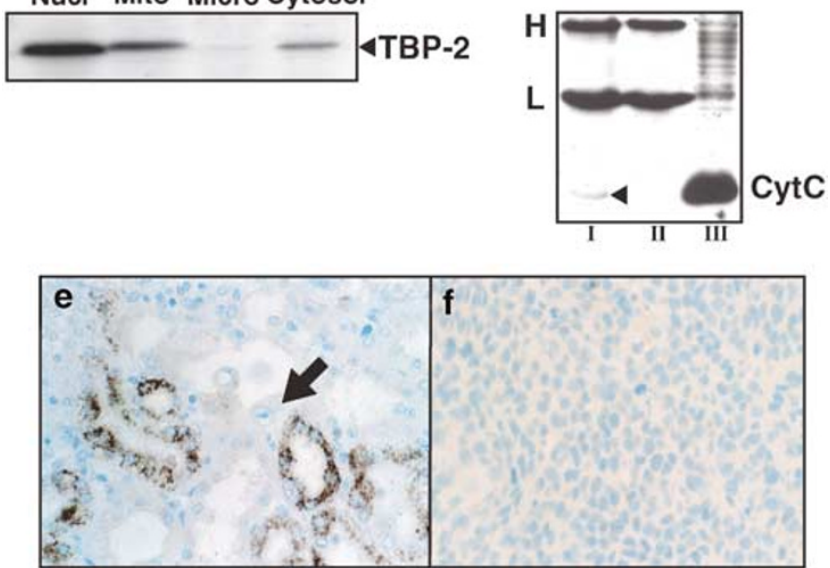

Figure 2 Immunochemical analysis of TBP-2. (a) Immunohistochemical analysis of rat untreated control kidney. Granular positivity was observed in the proximal tubular cells. GL, glomerulus (original magnification, $\times 200$ ). (b) Electronmicroscopic immunohistochemical analysis of rat control kidney. Inset shows magnified view of a mitochondrion. Mitochondrial intermembrane space and nucleus show electron-dense positivity. Nucl, nucleus (original magnification, $\times 7000$ ). (c) Western blot analysis of rat control kidney after fractionation. Nucl, nuclear fraction; Mito, mitochondrial fraction; Micro, microsomal fraction. See text for details. (d) Immunoprecipitation analysis showing the association of TBP-2 and cytochrome $c$. IP, immunoprecipitation; W, western blot analysis; $\mathrm{C}$, negative control $\mathrm{IgG}_{1}$ immunoglobulin; CytC, cytochrome $c$; H, immunoglobulin heavy chain; L, immunoglobulin light chain. Mitochondrial fraction $(1 \mu \mathrm{g})$ was run as a control at lane III. (e) Immunohistochemical analysis of a kidney 3 weeks after repeated administration of Fe-NTA. A karyomegalic cell (arrow) was negative for TBP-2. (f) Immunohistochemical analysis of $\mathrm{Fe}$ NTA-induced RCC. Tumor cells were negative (original magnification, $\times 200$ ).

\section{Subcellular Localization of TBP-2}

This study was performed on the untreated control kidney. Fractionation was performed by differential centrifugation to nuclear, mitochondrial, micro somal and cytosolic fractions, followed by confirmation with biochemical markers: DNA content, 196, 5.8, 0.0 and $2.4 \mu \mathrm{g} / \mathrm{mg}$ protein, respectively; succinate dehydrogenase activity, $0.0,800,0.0$ and $0.0 \mathrm{OD}$ at $490 \mathrm{~nm} / \mathrm{min} / \mathrm{mg}$ protein, respectively; NADPH-cytochrome $c$ reductase activity, 0.050, not applicable, 83.0 and $0.013 \mathrm{nmol} / \mathrm{min} / \mu \mathrm{g}$ protein, respectively; LDH activity, 16, 5.0, 14 and $100 \mathrm{mU} / \mathrm{mg}$ protein, respectively. Western blot analysis revealed that major amounts of TBP-2 were present in the nuclei and mitochondria, a small amount in the cytosol, and almost none in the microsomal fraction (Figure 2c). Immunohistochemistry at the electronmicroscopic level showed the presence of TBP-2 in the intermembrane space of mitochondria and nuclei (Figure 2b). Immunoprecipitation analyses of the mitochondrial fraction revealed the association of TBP-2 with cytochrome $c$ (Figure 2d).

\section{Mutational Analysis of TBP-2}

Rat TBP-2 genome sequences were obtained from the NCBI rat genome database. This gene was located on chromosome 2, and spanned $3875 \mathrm{bp}$ with eight exons. Positions -785 to -208 from the initiation ATG codon were categorized as a CpG island with a CpG island searcher program (http:// ccnt.hsc.usc.edu/cpgislands/) (Figure 3a). We found a unique type of deletion polymorphism in this CpG island producing interstrain differences at a potential site for methylation (Figure $3 \mathrm{~b}$ and c). The polyA tract in the distal part of the $3^{\prime}$ untranslated region (UTR) also showed some variation of the number of mononucleotide repeats in different strains of rats. In the Wistar and Fischer-344 strains, the number of repeats was 16, whereas it was 15 in the BrownNorway strain. Furthermore, the poly-A tract in the $3^{\prime}$ UTR was a frequent site for insertion and deletion mutations in the RCCs. The incidence of mutations was much lower in the coding exons and introns, and the mutations were all apparently silent (Table 2).

\section{CpG Island Methylation in the RCCs}

Methylation-specific PCR analysis revealed that all the tumors examined showed methylation at the examined position of $\mathrm{CpG}$ island in the promoter region of TBP-2 gene (Figure $3 \mathrm{~d}$ ).

\section{Association between TBP-2 and Cellular Proliferation}

Immunohistochemical analyses by the use of serial paraffin-embedded sections as well as Western blot analyses showed that PCNA positivity and TBP-2 positivity were inversely associated (Figures 1 and $4 a-d)$. After quantitating the results, the amounts of TBP-2 protein were significantly and inversely associated with the fraction of PCNA-positive cells with a certain threshold (Figure 4e). In the present study, TBP-2 protein was undetectable by Western blot analysis when the fraction of PCNApositive cells in the tissue was approximately more than $55 \%$. Within the range of $3-55 \%$ of PCNApositive cell fraction, the correlation coefficient was $r^{2}=0.988(P<0.01)$. 
a

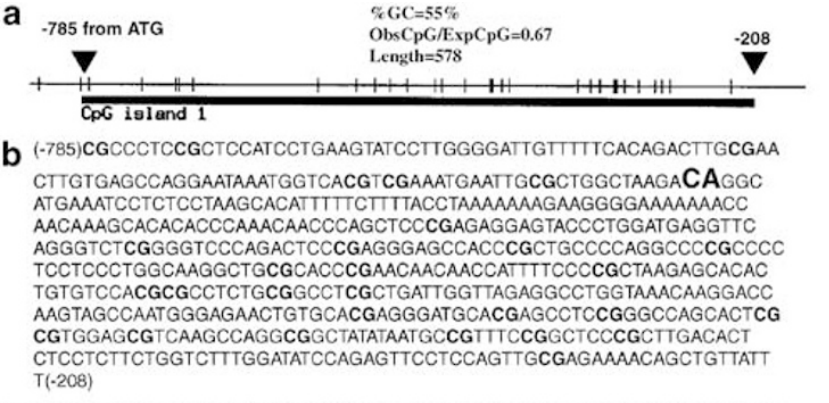

C (-786) CGCCCTCCGCTCCATCCTGAAGTATCCTTGGGGATTGTTTTICACAGACTTGCGAA CTTGTGAGCCAGGAATAAATGGTCACGTCGAAATGAATTGCGCTGGCTAAGACGAGGC ATGAAATCCTCTCCTAAGCACATTTTTCTTTTACCTAAAAAAAGAAGGGGAAAAAAACC AGGGTCTCGGGGTCCCAGACTCCCGAGGGAGCCACCCGCTGCCCCAGGCCCCGCCCC TCCTCCCTGGCAAGGCTGCGCACCCGAACAACAACCATTTT CCCCGCTAAGAGCACAC TGTGTCCACGCGCCTCTGCGGCCTCGCTGATTGGTTAGAGGCCTGGTAAACAAGGACC AAGTAGCCAATGGGAGAACTGTGCACGAGGGATGCACGAGCCTCCGGGCCAGCACTCG CGTGGAGCGTCAAGCCAGGCGGCTATATAATGCCGTTCCGGCTCCCGCTTGACACT CTCCTCTTCTGGTCTTTGGATATCCAGAGTTCCTCCAGTTGCGAGAAAACAGCTGTTATT $\mathrm{T}(-208)$

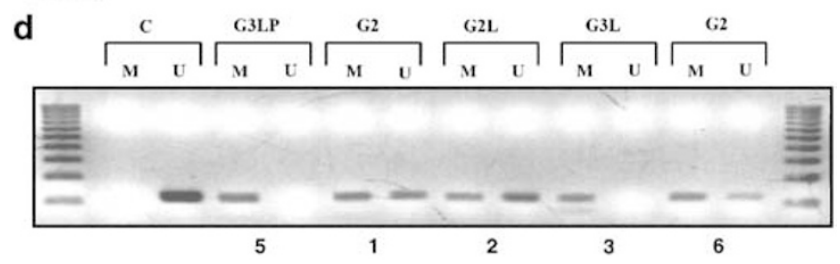

Figure 3 Genome structure and methylation-secific PCR analysis of rat TBP-2. (a) Structure of CpG island in the promoter region. (b) CpG island in the Brown-Norway strain. (c) CpG island in the Fischer-344 and Wistar strains. (d) Methylation-specific PCR analysis of TBP-2. All the tumors examined showed methylation at the CpG site amplified with the primer pairs shown in Table 2. Sample numbers shown at the bottom of Figure $3 \mathrm{~d}$ correspond with those of Figure 1 and Table 2. M, methylated; U, unmethylated; C, untreated control kidney; G2, grade-2; G3, grade-3; L, lung metastasis; P, peritoneal invasion.

\section{Discussion}

We found that the TBP-2 gene is one of the major target genes in Fe-NTA-induced renal carcinogenesis. The mode of inactivation was transcriptional silencing via $\mathrm{CpG}$ island methylation, as previously observed in one-third of the cases of inactivation of $p 15^{I N K 4 B}$ and $p 16^{I N K 4 A}$ tumor suppressor genes in this model..$^{15}$ Furthermore, loss of TBP-2 in human T-cell leukemia virus I-transformed cell lines was associated with aberrant methylation of $\mathrm{CpG}$ island region (Ahsan KM, Masutani $\mathrm{H}$ and Yodoi J, unpublished data). This suggests the presence of certain common mechanisms facilitating the methylation of $\mathrm{CpG}$ island regions during oxidative stressinduced carcinogenesis that should be further explored.

We also observed interstrain polymorphisms and several kinds of mutations (Figure $3 \mathrm{~b}, \mathrm{c}$ and Table 1). All the mutations were apparently silent. However, in this rather nonselective genomic environment we may be able to evaluate the unbiased spectrum of ROS-induced mutagenesis. We found a high incidence of single nucleotide insertions or deletions in the poly-A tract of the distal part of $3^{\prime}$ UTR. The C:G to T:A transition and G:C to T:A transversion mutations observed can be explained by the ROS-induced DNA base modifications. ${ }^{3}$

Furthermore, we found that a decrease in TBP-2 was associated with non-neoplastic cellular proliferation in vivo, namely, the regeneration of renal proximal tubules (Figure 1b). In this situation, however, ample amounts of message were observed (Figure 1c), suggesting that certain post-transcriptional mechanisms play a role in shortening the halflife of this protein. One of the plausible explanations is that certain organelles work as a temporary reservoir for TBP-2. This will be discussed later in detail. We then studied the relationship between cellular proliferation and the presence of TBP-2 protein, and found that a decrease in TBP-2 was closely associated with the presence of PCNA (Figures $1 \mathrm{~b}$ and $4 \mathrm{e}$ ). This was further confirmed by a morphological study revealing that TBP-2positive cells were negative for PCNA and vice versa (Figure 4a-d).

To elucidate the biological significance of the above observations, we examined the precise intracellular localization of TBP-2 in the rat kidney. The ubiquity of TBP-2 mRNA has been reported. However, we found an organ-specific difference in the amounts of TBP-2 protein (Figure 1a). We believe that this is due to the fact that most of the previous studies assessed only TBP-2 mRNA, not protein. Studies showed increased levels of TBP-2 mRNA after oxidative stress ${ }^{37}$ or glucose loading, ${ }^{38}$ and a decrease in the mRNA level in several human ${ }^{39-41}$ and animal tumors. ${ }^{42}$ Re-evaluation of these experiments may be necessary because of the inconsistency between the mRNA and protein levels of TBP-2.

Our fractionation study revealed that TBP-2 was present mainly in the nuclear and mitochondrial fractions in the renal proximal tubules (Figure 2c), which was consistent with the observation with immunostaining (Figure 2a). Immunohistochemical analysis at the electronmicoscopic level clearly showed that TBP-2 was present in the intermembrane space of mitochondria (Figure $2 b$ ) and in the nucleus. Cytochrome $C$ is a soluble protein that associates through electrostatic interactions with the outer surface of the mitochondrial inner membrane and is involved in complexes III and IV in the oxidative phophorylation, and its release to the cytoplasm is one of the signals for the start of apoptosis. ${ }^{43}$ In our immunoprecipitation study, we unexpectedly found that TBP-2 was associated with cytochrome $c$ (Figure $2 \mathrm{~d}$ ). Although the fraction of cytochrome $c$ bound to TBP-2 appears small, this confirms the presence of TBP-2 in the intermembrane space of the mitochondria.

Protein interaction of TBP-2 in mitochondria merits immediate attention. It is well known that renal proximal tubular cells are metabolically active and are rich in mitochondria. ${ }^{44}$ The precise role of 
Table 2 Mutational spectrum of the TBP-2 gene in Fe-NTA-induced renal cell tumors

\begin{tabular}{|c|c|c|c|c|c|c|c|}
\hline \multirow{2}{*}{$\begin{array}{l}\text { Tumor } \\
\text { sample ID }\end{array}$} & \multirow[t]{2}{*}{ Strain details } & \multicolumn{4}{|c|}{ Features of the tumors } & \multirow[t]{2}{*}{ Mutational change } & \multirow[t]{2}{*}{ Location of the mutation } \\
\hline & & $\begin{array}{l}\text { Lung } \\
\text { metastasis }\end{array}$ & $\begin{array}{l}\text { Peritoneal } \\
\text { invasion }\end{array}$ & Size $(\mathrm{mm})$ & $\begin{array}{l}\text { Histology } \\
\text { and grading }\end{array}$ & & \\
\hline $16-5^{\mathrm{a}}$ & $\mathrm{W}$ & - & - & 10 & Adenoma & $\begin{array}{l}\text { Single nucleotide } \\
\text { (A) insertion }\end{array}$ & $\begin{array}{l}\mathrm{A}_{16} \text { tract in the distal part of } 3^{\prime} \text { UTR } \\
(+3571 \rightarrow+3586)\end{array}$ \\
\hline $2-1$ & $\mathrm{~W}$ & + & + & 90 & RCC grade 2 & $\begin{array}{l}\text { Single nucleotide } \\
\text { (A) insertion } \\
\mathrm{C} \rightarrow \mathrm{T}\end{array}$ & $\begin{array}{l}A_{16} \text { tract in the distal part of } 3^{\prime} \text { UTR } \\
(+3571 \rightarrow+3586) \\
\text { Promoter }(-311)\end{array}$ \\
\hline $7-1^{\mathrm{a}}(1)^{\mathrm{b}}$ & $\mathrm{F} 1(\mathrm{~F} \times \mathrm{BN})$ & - & - & 20 & RCC grade 2 & $\mathrm{~A} \rightarrow \mathrm{T}$ & Coding sequence, synonymous (+1081) \\
\hline 7-7 (2) & $\mathrm{F} 1(\mathrm{~F} \times \mathrm{BN})$ & + & - & 60 & RCC grade 2 & - & 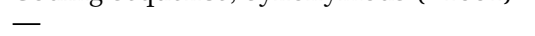 \\
\hline $14-1$ & $\mathrm{~W}$ & + & - & 17 & RCC grade 2 & $\begin{array}{l}\mathrm{G} \rightarrow \mathrm{T} \\
\text { Single nucleotide } \\
\text { (A) insertion }\end{array}$ & $\begin{array}{l}3^{\prime} \text { UTR }(+3158) \\
\mathrm{A}_{16} \text { tract in the distal part of } 3^{\prime} \text { UTR } \\
(+3571 \rightarrow+3586)\end{array}$ \\
\hline $15-3(6)$ & W & - & - & 50 & RCC grade 2 & - & - \\
\hline $48-5$ & $\mathrm{~F} 1(\mathrm{~F} \times \mathrm{BN})$ & - & - & 20 & RCC grade 2 & - & - \\
\hline 14-6(5) & $\mathrm{F} 1(\mathrm{~F} \times \mathrm{BN})$ & + & + & 30 & RCC grade 3 & $\begin{array}{l}\text { Single codon } \\
\text { (AAC) deletion } \\
\text { Single nucleotide } \\
\text { deletion (A) }\end{array}$ & $\begin{array}{l}\text { Coding sequence, carboxy-terminal } \mathrm{Asn}_{6} \\
\text { tract }(+2218 \rightarrow+2235) \\
\mathrm{A}_{15} \text { tract in the distal part of } 3^{\prime} \text { UTR } \\
(+3571+3586)\end{array}$ \\
\hline $15-4$ & $\mathrm{~W}$ & + & + & 40 & RCC grade 3 & $\begin{array}{l}\mathrm{G} \rightarrow \mathrm{A} \\
\text { Single nucleotide } \\
\text { deletion (A) }\end{array}$ & $\begin{array}{l}\text { Intronic sequence }(+1223) \\
A_{7} \text { in the } C p G \text { island }(-616 \rightarrow-622)\end{array}$ \\
\hline $16-1$ & $\mathrm{~W}$ & + & - & 40 & RCC grade 3 & $\begin{array}{l}\text { Single nucleotide } \\
\text { (A) insertion }\end{array}$ & $\begin{array}{l}\mathrm{A}_{16} \text { tract in the distal part of } 3^{\prime} \text { UTR } \\
(+3571+3586)\end{array}$ \\
\hline $30-5(4)$ & $\mathrm{F} 1(\mathrm{~F} \times \mathrm{BN})$ & + & + & 60 & RCC grade 3 & - & - \\
\hline $45-4(3)$ & $\mathrm{F} 1(\mathrm{~F} \times \mathrm{BN})$ & + & - & 40 & RCC grade 3 & - & - \\
\hline
\end{tabular}

RCC, renal cell carcinoma; W, Wistar strain; F, Fischer strain; BN, Brown-Norway strain; UTR, untranslated region.

${ }^{\mathrm{a}}$ Showed small amount of TBP-2 protein by Western blot analysis. TBP-2 protein was undetectable in all the other tumors.

${ }^{b}$ Numbers in the parentheses after tumor sample ID correspond to the tumor numbers in Figures 1b and 3d. Refer to text for details. 


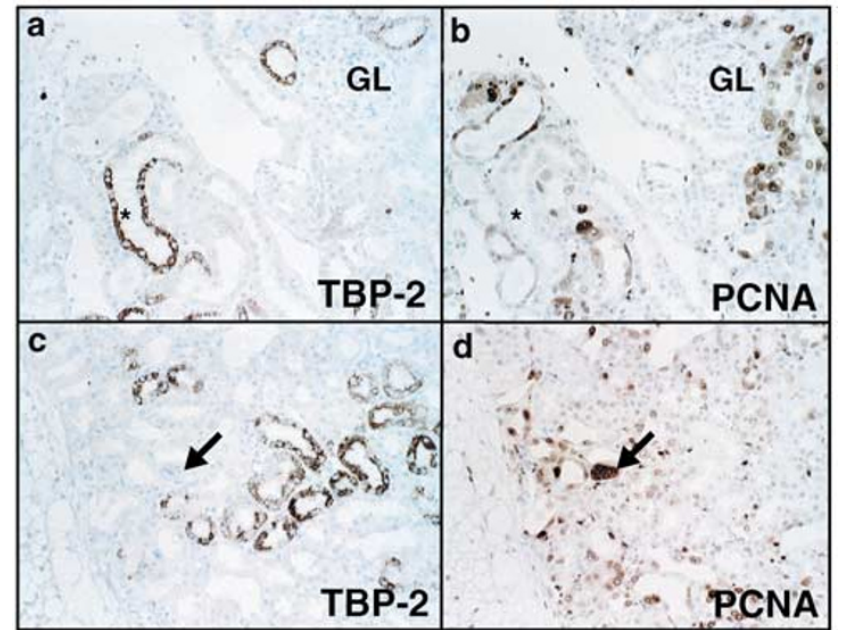

e

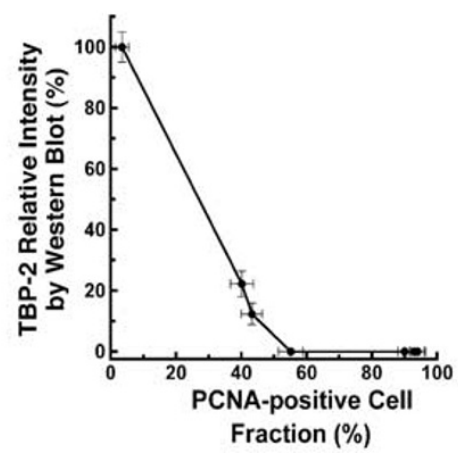

Figure 4 Inverse association of TBP-2 and cellular proliferation in vivo. (a) and (c) Immunohistochemical analysis of TBP-2 in the kidney after repeated Fe-NTA adminstration of 3 weeks. (b) and (d) Immunohistochemical analysis of PCNA in the kidney after the same repeated Fe-NTA adminstration (original magnification, $\times 200$ ). (a and b), (c and $\mathbf{d}$ ) are paired serial sections, and asterisks and arrows show identical positions. TBP-2-positive cells and PCNA-positive cells were complementary to each other. (e) Inverse association between PCNA-positive cell fraction and amounts of TBP-2 protein. The amount of TBP-2 by Western blot analysis was quantified with NIH image freeware as described in the Materials and methods section. PCNA-positive cell fraction was determined by counting positive cells at five randomly selected areas $(\times 200$ magnification). Three samples of renal tissues were used for each point (control, $24 \mathrm{~h}, 48 \mathrm{~h}, 3$ weeks, RCCs; $N=3$, means \pm s.e.m.). Within the range of $3-55 \%$ of PCNApositive cell fraction, an inverse correlation was observed between the amount of TBP-2 protein and cellular proliferation. Refer to text for details.

TBP-2 in the renal proximal tubules is unknown so far, but there are possible functions from at least three standpoints.

First, TBP-2 was reported as VDUP-1 in HL-60 leukemia cells. $^{24}$ HL-60 cells differentiate into monocytes or macrophages on exposure to vitamin $\mathrm{D}_{3} \cdot{ }^{45}$ Vitamin $\mathrm{D}$ is a seco-steroid whose actions are dependent on several steps catalyzed by cytochrome $P 450$ enzymes. The first of these steps is carried out in the liver by the enzyme 25-hydroxylase, which catalyzes the synthesis of 25-hydroxyvitamin $D_{3}$ $\left(25(\mathrm{OH}) \mathrm{D}_{3}\right)$, the major circulating form of vitamin $\mathrm{D}_{3}$. The $25(\mathrm{OH}) \mathrm{D}_{3}$ is then converted to the active form of vitamin $\mathrm{D}$, dihydroxyvitamin $\mathrm{D}_{3}$, by the enzyme 25-hydroxyvitamin $D_{3}-1 \alpha$-hydroxylase present in the mitochondria of renal proximal tubules. ${ }^{46}$ TBP-2 was indeed accumulated in the location where vitamin $\mathrm{D}$ is activated.

Second, TBP-2 is a binding protein of Trx. The ubiquitous enzyme Trx is responsible for equilibrating the $\mathrm{NAD}(\mathrm{P}) \mathrm{H} / \mathrm{NAD}^{+}(\mathrm{P})$ redox potential together with the protein sulfhydryl redox state via the oxidation of NADPH. We have reported that Trx function can be modulated by the interaction with its inhibitory protein, TBP-2. ${ }^{23}$ Recently, studies of a TBP-2-null mutant mouse ${ }^{25}$ provided evidence that loss of TBP-2 results in enhanced sulfhydryl reduction and dysregulated carbohydrate and lipid metabolism, namely hyperinsulinemia, hypoglycemia, hypertriglyceridemia and increased levels of ketone bodies, at least in the liver and pancreatic $\beta$-cells. ${ }^{47}$ On the other hand, it was shown that hyperglycemia inhibits the ROS-scavenging function of Trx through p38 MAPK-induction of TBP-2. ${ }^{48}$ In the present study of renal carcinogenesis, loss of TBP-2 protein was induced only in a certain fraction of the renal tubular cells after Fe-NTA treatment and in the cancer cells (Figure 2e and f). Loss of TBP-2 appears advantageous in cancer cells because it results in facilitation of the glycolytic pathway ${ }^{47}$ in addition to the promotion of cellular proliferation since hypoxia is often associated with tumor growth. In a yeast two-hybrid screening using TBP-2 as bait, several clones encoding Trx2 were identified, demonstrating the interaction of TBP-2 with Trx2 in vitro (Wang $\mathrm{D}$, Masutani $\mathrm{H}$ and Yodoi J, unpublished data). Studies are in progress to clarify the association among TBP-2, Trx2 and cytochrome $c$.

Third, mitochondria may work as a temporary reservoir for TBP-2. The nucleus appears to be the final destination of this protein. We found that TBP2 ectopically expressed in the breast cancer cell line MCF-7 was localized predominantly in the nucleus exhibiting growth suppressive activity. ${ }^{49}$ It was also reported that TBP-2 interacts with promyelocytic leukemia zinc-finger, Fanconi anemia zinc-finger and histone deacetylace 1, which are known to be transcriptional corepressors. ${ }^{41}$ As a nuclear transport system, we recently identified importin $\alpha_{1}$ (Rch1) as a protein interacting with TBP-2. The expression of short interfering RNA of importin $\alpha_{1}$ suppressed suberoylanilide hydroxamic acid-induced nuclear accumulation of TBP-2.49,50 Renal function is essential for the survival of the individual. A regulatory mechanism to maintain the renal tubular function by inhibiting mitosis may be necessary when a low level of damage occurs in the mitochondria of renal proximal tubules. In the Fe-NTA model, we previously reported that the mitochondria are major target organelles in the acute renal tubular injury by Fe-NTA. ${ }^{51}$ It is possible that mild damage to mitochondria induces a release of TBP-2 to nuclei, leading to inhibition of mitosis. Severe damage or loss of 
mitochondria may lead to loss of TBP-2 protein, resulting in a signal for mitosis. Renal proximal tubule is a site that merits further investigation of TBP-2 function in vivo.

In conclusion, TBP-2 protein is abundant in the mitochondria of the rat renal proximal tubular cells, where vitamin $\mathrm{D}$ is converted to an active form, and in the nuclei of these cells. TBP-2 expression is transcriptionally silenced in Fe-NTA-induced RCCs of rats by aberrant promoter methylation. Loss of TBP-2 is intimately associated with renal tubular proliferation in vivo irrespective of the molecular mechanisms involved and whether such proliferation is neoplastic or non-neoplastic.

\section{Acknowledgements}

We thank Ms Waka Kawaguchi for excellent technical assistance. This work was supported in part by a Grant-in-Aid from the Ministry of Education, Science, Sports and Culture of Japan and a Grantin-Aid for Cancer Research from the Ministry of Health, Labour and Welfare of Japan. The sequences reported in this paper have been deposited in the DDBJ/EMBL/GenBank database (Accession: AB189076 and AB189077).

\section{References}

1 Ames BN, Shigenaga MK, Park E-M. DNA damage by endogenous oxidants as a cause of aging and cancer. In: Davies KJA (ed). Oxidative Damage and Repair: Chemical Biological and Medical Aspects. Pergamon Press: New York, 1991, pp 181-187.

$2 \mathrm{Wu}$ T, Sempos C, Freudenheim J, et al. Serum iron, copper and zinc concentrations and risk of cancer mortality in US adults. Ann Epidemiol 2004;14: 195-201.

3 Toyokuni S. Iron-induced carcinogenesis: the role of redox regulation. Free Radic Biol Med 1996;20: $553-566$.

4 Ebina Y, Okada S, Hamazaki S, et al. Nephrotoxicity and renal cell carcinoma after use of iron- and aluminum- nitrilotriacetate complexes in rats. J Natl Cancer Inst 1986;76:107-113.

5 Li JL, Okada S, Hamazaki S, et al. Subacute nephrotoxicity and induction of renal cell carcinoma in mice treated with ferric nitrilotriacetate. Cancer Res 1987;47:1867-1869.

6 Toyokuni S, Okada S, Hamazaki S, et al. Combined histochemical and biochemical analysis of sex hormone dependence of ferric nitrilotriacetate-induced renal lipid peroxidation in $\mathrm{ddY}$ mice. Cancer Res 1990;50:5574-5580.

7 Toyokuni S. Reactive oxygen species-induced molecular damage and its applicaton in pathology. Pathol Int 1999;49:91-102.

8 Zhang D, Okada S, Yu Y, et al. Vitamin E inhibits apoptosis, DNA modification, and cancer incidence induced by iron-mediated peroxidation in Wistar rat kidney. Cancer Res 1997;57:2410-2414.
9 Toyokuni S, Mori T, Dizdaroglu M. DNA base modifications in renal chromatin of Wistar rats treated with a renal carcinogen, ferric nitrilotriacetate. Int J Cancer 1994;57:123-128.

10 Toyokuni S, Tanaka T, Hattori Y, et al. Quantitative immunohistochemical determination of 8-hydroxy-2'deoxyguanosine by a monoclonal antibody N45.1: its application to ferric nitrilotriacetate-induced renal carcinogenesis model. Lab Invest 1997;76:365-374.

11 Toyokuni S, Mori T, Hiai H, et al. Treatment of Wistar rats with a renal carcinogen, ferric nitrilotriacetate, causes DNA-protein cross-linking between thymine and tyrosine in their renal chromatin. Int J Cancer 1995;62:309-313.

12 Toyokuni S, Uchida K, Okamoto K, et al. Formation of 4-hydroxy-2-nonenal-modified proteins in the renal proximal tubules of rats treated with a renal carcinogen, ferric nitrilotriacetate. Proc Natl Acad Sci USA 1994;91:2616-2620.

13 Uchida K, Fukuda A, Kawakishi S, et al. A renal carcinogen ferric nitrilotriacetate mediates a temporary accumulation of aldehyde-modified proteins within cytosolic compartment of rat kidney. Arch Biochem Biophys 1995;317:405-411.

14 Toyokuni S, Luo XP, Tanaka $\mathrm{T}$, et al. Induction of a wide range of $\mathrm{C}_{2-12}$ aldehydes and $\mathrm{C}_{7-12}$ acyloins in the kidney of Wistar rats after treatment with a renal carcinogen, ferric nitrilotriacetate. Free Radic Biol Med 1997;22:1019-1027.

15 Tanaka T, Iwasa Y, Kondo S, et al. High incidence of allelic loss on chromosome 5 and inactivation of $p 15^{I N K 4 B}$ and $p 16^{I N K 4 A}$ tumor suppressor genes in oxystress-induced renal cell carcinoma of rats. Oncogene 1999;18:3793-3797.

16 Hiroyasu M, Ozeki M, Kohda H, et al. Specific allelic loss of $p 16^{I N K 4 A}$ tumor suppressor gene after weeks of iron-mediated oxidative damage during rat renal carcinogenesis. Am J Pathol 2002;160:419-424.

17 Tanaka T, Akatsuka S, Ozeki M, et al. Redox regulation of annexin 2 and its implications for oxidative stessinduced renal carcinogenesis and metastasis. Oncogene 2004;23:3980-3989.

18 Nakamura H, Nakamura K, Yodoi J. Redox regulation of cellular activation. Annu Rev Immunol 1997;15: 351-369.

19 Nishiyama A, Masutani H, Nakamura H, et al. Redox regulation by thioredoxin and thioredoxin-binding proteins. IUBMB Life 2001;52:29-33.

20 Tanaka T, Nakamura H, Nishiyama A, et al. Redox regulation by thioredoxin superfamily; protection against oxidative stress and aging. Free Radic Res 2001;33:851-855.

21 Holmgren A. Thioredoxin. Annu Rev Biochem 1985; 54:231-237.

22 Haendeler J, Hoffmann J, Tischler V, et al. Redox regulatory and anti-apoptotic functions of thioredoxin depend on $S$-nitrosylation at cysteine 69. Nat Cell Biol 2002;4:743-749.

23 Nishiyama A, Matsui M, Iwata S, et al. Identification of thioredoxin-binding protein-2/vitamin $D_{3}$ up-regulated protein 1 as a negative regulator of thioredoxin function and expression. J Biol Chem 1999;274:2164521650.

24 Chen K, De Luca $\mathrm{H}$. Isolation and characterization of a novel cDNA from HL-60 cells treated with 1,25-dihydroxyvitamin D-3. Biochim Biophys Acta 1994;1219:26-32. 
25 Bodnar J, Chatterjee A, Castellani L, et al. Positional cloning of the combined hyperlipidemia gene Hyplip1. Nat Genet 2002;30:110-116.

26 Nishinaka Y, Nishiyama A, Masutani H, et al. Loss of thioredoxin-binding protein-2/vitamin D3 up-regulated protein 1 in human T-cell leukemia virus type I-dependent T-cell transformation: implications for adult T-cell leukemia leukemogenesis. Cancer Res 2004;64:1287-1292.

27 Nishiyama Y, Suwa $\mathrm{H}$, Okamoto K, et al. Low incidence of point mutations in $\mathrm{H}-, \mathrm{K}$ - and $\mathrm{N}$-ras oncogenes and p53 tumor suppressor gene in renal cell carcinoma and peritoneal mesothelioma of Wistar rats induced by ferric nitrilotriacetate. Jpn J Cancer Res 1995;86:1150-1158.

28 Tanaka T, Nishiyama Y, Okada K, et al. Induction and nuclear translocation of thioredoxin by oxidative damage in the mouse kidney: independence of tubular necrosis and sulfhydryl depletion. Lab Invest 1997; 77:145-155.

29 Seol K, Kim S. Nuclear matrix association of insulin receptor and IRS-1 by insulin in osteoblast-like UMR106 cells. Biochem Biophys Res Commun 2003; 306:898-904.

30 Yamaguchi M, Tsurusaki Y, Misawa H, et al. Potential role of regucalcin as a specific biochemical marker of chronic liver injury with carbon tetrachloride administration in rats. Mol Cell Biochem 2002;241:61-67.

31 Phillips AH, Langdon RG. Hepatic triphosphopyridine nucleotide-cytochrome $c$ reductase: isolation, characterization and kinetic studies. J Biol Chem 1962; 237:2652-2660.

32 Vermilion J, Coon M. Purified liver microsomal NADPH-cytochrome $P-450$ reductase. Spectral characterization of oxidation-reduction states. J Biol Chem 1978;253:2694-2704.

33 Kaplan LA, Pesce AJ. Clinical Chemistry, Theory, Analysis and Correlation. Mosby: St Louis, 1989.

34 Toyokuni S, Kawaguchi W, Akatsuka S, et al. Intermittent microwave irradiation facilitates antigen-antibody reaction in Western blot analysis. Pathol Int 2003;53:259-261.

35 Sambrook J, Fritsch EF, Maniatis T. Molecular Cloning: A Laboratory Manual. Cold Spring Harbor Laboratory Press: Cold Spring Harbor, NY, 1989.

36 Herman JG, Graff JR, Myohanen S, et al. Methylationspecific PCR: a novel PCR assay for methylation status of CpG islands. Proc Natl Acad Sci USA 1996;93: 9821-9826.

37 Junn E, Han S, Im J, et al. Vitamin D3 up-regulated protein 1 mediates oxidative stress via suppressing the thioredoxin function. J Immunol 2000;164:6287-6295.
38 Hirota T, Okano T, Kokame K, et al. Glucose downregulates Per1 and Per2 mRNA levels and induces circadian gene expression in cultured Rat-1 fibroblasts. J Biol Chem 2002;277:44244-44251.

39 Ikarashi M, Takahashi Y, Ishii Y, et al. Vitamin D3 up-regulated protein 1 (VDUP1) expression in gastrointestinal cancer and its relation to stage of disease. Anticancer Res 2002;22:4045-4048.

40 Takahashi Y, Nagata T, Ishii Y, et al. Up-regulation of vitamin D3 up-regulated protein 1 gene in response to 5 -fluorouracil in colon carcinoma SW620. Oncol Rep 2002;9:75-79.

41 Han S, Jeon J, Ju H, et al. VDUP1 upregulated by TGF$\beta 1$ and 1,25-dihydorxyvitamin D3 inhibits tumor cell growth by blocking cell-cycle progression. Oncogene 2003;22:4035-4046.

42 Young L, Yang X, Voigt J. Alteration of gene expression in rat mammary tumors induced by $N$-methyl- $N$ nitrosourea. Mol Carcinog 1996;15:251-260.

43 Desagher S, Martinou J. Mitochondria as the central control point of apoptosis. Trends Cell Biol 2000; 10:369-377.

44 Rhodin JAG. Histology: A Text and Atlas. Oxford University Press: New York, 1974.

45 Miyaura C, Abe E, Kuribayashi T, et al. 1 $\alpha$, 25Dihydroxyvitamin D3 induces differentiation of human myeloid leukemia cells. Biochem Biophys Res Commun 1981;102:937-943.

46 Hewison M, Zehnder D, Bland R, et al. $1 \alpha$-Hydroxylase and the action of vitamin D. J Mol Endocrinol 2000;25: 141-148.

47 Hui T, Sheth S, Diffley J, et al. Mice lacking thioredoxin interacting protein provide evidence linking cellular redox state to appropriate response to nutritional signals. J Biol Chem 2004;279:2438724393.

48 Schulze P, Yoshioka J, Takahashi T, et al. Hyperglycemia promotes oxidative stress through inhibition of thioredoxin function by thioredoxin-interacting protein. J Biol Chem 2004;279:30369-30374.

49 Nishinaka Y, Masutani H, Oka S, et al. Importin $\alpha 1$ (Rch1) mediates nuclear translocation of thioredoxinbinding protein-2/vitamin D3-up-regulated protein 1. J Biol Chem 2004;279:37559-37565.

50 Butler L, Zhou X, Xu W, et al. The histone deacetylase inhibitor SAHA arrests cancer cell growth, up-regulates thioredoxin-binding protein-2, and down-regulates thioredoxin. Proc Natl Acad Sci USA 2002;99: 11700-11705.

51 Hamazaki S, Okada S, Ebina Y, et al. Nephrotoxicity of ferric nitrilotriacetate. An electron-microscopic and metabolic study. Am J Pathol 1986;123:343-350. 